\title{
Impact of teacher qualification on students' achievement in Science
}

\author{
Kamal Prasad Koirala \\ Lecturer, Science Education, Gorkha Campus, Gorkha \\ Dr. Gem Prasad Gurung \\ Associate Professor, Sanothimi Campus, Sanothimi, Bhaktapur \\ Prakash Wagle \\ School Science Teacher, Gorkha
}

\begin{abstract}
This paper analyzed the teachers' qualification and its impact on students' science achievement in Gorkha district. The purpose of this study was to find out the impact of teacher qualification on student achievement in science teaching and to compare the science achievement of the students taught by trained and untrained teachers. The nature of this study is a mixed-method approach with survey design. To fulfil the objectives of the study, the researchers selected 15 public schools from Gorkha district as a sample, where 5 schools have under Bachelor's Graduates and 5 schools have Bachelor's or above graduates but have not teachers' professional development (TPD) training and 5 schools have Bachelor's or above graduates having TPD training science teachers. For this study, 15 science teachers and 672 students were selected as a sample by random sampling method. The researchers reviewed the District Level Examination (DLE) result of Gorkha district in the academic year 2016/17. The data was collected from the district education office document of Gorkha district. The primary data were collected through one-week classroom observation and students' interviews. The study shows that higher qualification teachers, as well as trained teachers, have more techniques and skills of teaching, using methods, materials, evaluation scheme, feedback and other extra activities than the lower qualification and untrained teachers. Also, the result indicates that the science achievement of students taught by trained teachers is greater than the students taught by untrained teachers. Therefore, teacher professional development training and qualification have a positive impact on science learning.
\end{abstract}

Keywords: Professional development, teacher training, students' achievement, teachers' qualification, instruction 


\section{Introduction}

The science teachers are taken as an epitome of the teaching-learning process. Science teachers are in heart of the teaching-learning process. According to Rousseau, the child is a book which the teacher has to learn from page to page (Sharma \& Sharma, 2066 BS). Many research studies found that teachers' qualification is an important factor for promoting students' science achievement (Acharya, 2015). The quality of education depends upon various factors which are related to various dimension such as philosophy of education of the nation, school goals, social aims, teachers' qualification, school administration and so on which worked as the determining factors of science achievement of students in the context of developing countries like Nepal.

The Nepalese education system is practice-based and teacher-driven, so the teachers are considered as the centre of the teaching-learning process. Moreover, teacher's educational background, qualification, professional skills and competency also determine the quality of education in the context of the Nepalese education system (Mohan, 2013). Teachers' role is always prominent in improving students' achievement and innovative teaching. However, it is being challenged in the context of Nepal (Avramidis \& Kalyva, 2007). Both teacher qualification and teacher training are important teacher-related factors that affect the students' science achievement (Koirala, 2074 BS). There are several teacher-related factors which directly influence the teaching-learning process such as age, gender, professional development, qualification, experience, etc. Among them, qualification is the most important factor that affects students' achievement (Avramidis \& Kalyva, 2007). A different study shows that teacher qualification has a significant impact on education in developing countries (Lockheed, 1988), which is found relevant to implement in the context of Nepalese scenario.

The teacher characteristics such as teacher qualifications, level of degrees, years of experience, preparation in subject matter and pedagogy, use of technology, certification in their expertise area and their ongoing professional development and student learning (Koirala, 2019; Mohan, 2013) impact on the student achievement in science learning. In many countries, teacher's qualification that is considered to be related to student learning has become a desirable target of teacher education reform. Some of these reforms call for the professionalization of teacher education by making it longer upgrading it to graduate programmes and regulating it through 
mechanisms of licene, certification and promotion aligned with standards (DarlingHammand, 1999).

\section{Educational Commissions and Condition of Professional Development in Nepal}

Nepalese secondary level teachers are found having been trained in subject matter and teaching pedagogy. However, these are themselves not to meeting the learning needs of students (Koirala, in press). According to the Education Act 1971 with subsequent amendments, the basic qualification for primary level is School Leaving Certificate (SLC) with training, Lower Secondary is Proficiency Certificate Level (PCL) or equivalence qualification with training and for Secondary level is Bachelor's Degree with training. Now the school structure is going to be changed made by 8th amendments of Education Act 1971. In National Education System Plan (NESP) (1971-76), Government of Nepal made a systematic and concentrated effort to improve the quality of education of the school system. The government emphasized the need of the trained teachers of all level and the NESP is consonance to maintain qualified teachers stated of the following to improve the condition of the service of teachers (MoE, 2016).

National Education Policy 2076 also emphasizes to raise the quality of the teachers and the teaching profession (MoEST, 2076 a). To raise the quality of the teachers, it is necessary to improve the teachers' qualification. The qualification of teachers plays an important role to increase the achievements of students in the formal school system. So those teachers are considered as a single decisive factor governing the achievements of students.

Intending to establish the relationship between science teacher quality and students' achievement, it is important to carry out such research as science teachers play a crucial role in student's academic achievement (MoEST, 2076a). Different studies show that poor performance in Maths and Science highly contributes to the overall low achievement of students in Nepal. The teacher's professional training was chosen for the study and not the other school factors because the teacher is the most critical factor in the organization of knowledge imparted to the learners and the instructional materials used in the implementation of the curriculum (Hopkins \& Harris, 1997).

In Nepal teachers' Professional Development (PD) has been passing through many ups and downs since the establishment of the College of Education in 1956 AD based on NNEPC 1954. The effort of the College of Education in teacher 
professional development is commendable due to its long term visioning on the teacher education programme in Nepal (CERID, 1996). The contribution of College of Education to teacher professional development has been augmented by the establishment of National Centre for Educational Development (NCED) in 1992 as a milestone for the cause of professional development of teacher under the Ministry of Education (MOE), as recommended by NCE, 1992. After the establishment of NCED, the overall responsibility to provide training to the school teacher went to NCED (NCED, 2006). School Sector Development Plan [SSDP) has tried student-centred teaching in Maths, Science and English focusing on professional development (PD) workshop and seminar that emphasizes the student-centred teaching (MoE, 2016). Only PD training is considered as a mean for transforming the teachers. However, "insufficient access to resources, lack of instructional support, lack of development opportunities, and lack of confidence could negatively influence in science teaching" (Affouneh et al., 2020, p. 3). Tribhuvan University, Faculty of Education tries to produce professionally trained science teachers. However, questions are aroused upon its effectiveness.

This study also identifies the students' view of their teaching qualification. There is an assumption that qualified teachers teach the better than that of other teachers. The qualification provides precise insight into the profession. Teacher qualification provides the knowledge and skills of an innovative method of teaching, the current change in content and context, analyzed the job market and provided the education on the demands of contemporary society (Mohan, 2013). The study on student's perception suggests that good interaction, collaborative class environment, and teacher help with their students play a vital role to increase the satisfaction level of students (Sood, 1989). So, this study also tries to investigate the concerning fact.

The greater failure at SLC is due to the student underachievement at lower secondary and under another level (MoEST, 2076b). Some international studies show that there is a strong relationship between teacher's characteristics such as qualification and students achievement (MoE, 2016). In our context teacher qualification is a heated debate in the sphere of educational sector. Whether the qualification of teacher supports the educational contribution in our country is a part of research which needs to be conducted.

Science instruction today must be broader and more inclusive than in the past if it is to meet the increasing demands being made on the scientific competence of students (Sood, 1989). The science instruction must do more than to meet the goals 
of science, which includes these skills and techniques. In the context of Nepal, the quality of teaching science in school education also does not seem to be improved with the availability of qualified teachers. From the discussion, it can be claimed that teachers' qualification is related to measure of students' achievement (Koirala, in press). Therefore, the researchers are interested in carrying out the study on the role of teachers' qualification in the achievement level of grade VIII students of Gorkha district.

This study is concerned with the relation between teacher qualification and student achievement in Gorkha district. The qualification itself is a broad term that can simply be defined as academic achievement, academic accreditation and achievement (Mohan, 2013) which can be defined as a score get by students in a DLE in 2016/17.

The main concern of this study was how teachers' qualification is a determinable factor of student achievement and their satisfaction. Precisely this study tries to achieve the following objectives:

1. To analyze the effect of teacher's qualification on science teaching

2. To compare the relation between student's achievement in science taught by under bachelor's graduate teachers and bachelor's or above bachelor's graduates teachers

3. To compare the relation between student's achievements in science taught by the trained and untrained teachers

4. To explore the students' perception of science teaching in relation to teachers' qualification.

Science is an essential component of school and higher education. The degree of achievement level in the science of students depends on many internal and external factors. Many studies show that the teachers' qualification and their involvement in students' study play a vital role on students' achievement.

\section{Research Hypothesis}

The researchers stated the following hypothesis to reach at the definite conclusion about the problem, previously stated:

1. There is no significant difference between science achievement of the students taught by under bachelor's graduate teachers, bachelor's or above bachelor's graduate teachers. 
2. There is no significant difference between the science achievement of the students taught by the trained and untrained teachers.

\section{Methods and Procedures}

This study had tried to find out the science achievement level and perception of students in relation to teacher qualification based on mixed method research design (Creswell, 2012). So all the schools who appeared in DLE of the academic year 2016/17 in Gorkha district (i.e. 183 schools) were the population of this study. This study was conducted only in Gorkha district. Science teachers were purposively selected from 15 schools (public), both lower secondary and secondary science teachers' of grade VIII, and the teachers were divided into three groups called group A, group B and group C. Where group A means the teachers having under bachelor's qualification, group B denotes teachers' having bachelor's or above bachelor's qualification and group $\mathrm{C}$ denotes teacher having higher qualification and having TPD training. Each group contained five teachers. 210 students from group A, 191 students from group B and 271 students from group C (altogether 672 students) were the sample from secondary data that is a result of DLE 2016/17 of Gorkha district. One school from each category was selected through convenience sampling method. Altogether there are three schools for classroom observation. At the same time, three students from each school were randomly selected for student's interview. The researchers observed the science classroom of three schools taught by under bachelor's graduated teachers, bachelor's or above graduate teachers and bachelor's or above graduates and having TPD training teachers respectively.

\section{Document Analysis}

The researchers collected secondary data from district level examination of the previous year (i.e. 2016/17) of fifteen schools in Gorkha district. Altogether 672 students' results were analyzed. The data were found in the district education office. The result was further analyzed based on teachers' qualification and out of them researchers took five school results taught by under bachelor's graduate teachers. There were 210 students', and five school results taught by bachelor's or above bachelor's graduate teacher. There were 191 students' and five school results taught by bachelor's graduate, and having TPD training teachers, there were 271 students. 


\section{Data Collection Procedure}

The researchers reviewed the DLE results of Gorkha district in the academic year 2016/17 and divided into the three groups based on teacher's qualification. This data was collected from the district education office document of Gorkha district. The primary data were collected through classroom observations and students' interviews. From each category, researchers randomly selected one school for classroom observation. The researchers observed the classroom of each category of the teacher during one week based on classroom observation guideline. Similarly, the researchers conducted students' interviews with three students from each observed school. Altogether 9 students participated in the interview.

\section{Data Analysis Procedure}

The researchers analyzed the obtained data by using the statistical procedure. Statistical Package for Social Science (SPSS 20 version) widely uses quantitative data analysis software, so the researchers analysed the obtained data by using SPSS software. Descriptive information on teacher qualification and students achievement score was analysed through calculating mean and standard deviation. Its significance was tested by one-way ANOVA test. Again, the difference between the mean scores of two groups of the student at a time was calculated by t-test at 0.05 level of significance with the help of SPSS. The primary data were analyzed by categorizing and by making themes.

\section{Results}

The analysis and interpretation is based on science achievement of students taught by under bachelor's graduate teachers, bachelor's or above graduate teachers and bachelor's or above graduate as well as having TPD training teachers. On the other hand, this deals the analysis of students' perception level relating to their teacher qualification and classroom teaching strategy.

The difference between the mean scores of two groups and t-test are given below.

The first hypothesis was "There is no significant difference between science achievement of the students taught by under bachelor's graduate teacher and bachelor's or above graduate teachers of Grade VIII." 
Table 1

Comparison of Mean Scores of Students Taught by Under Bachelor Graduate Teachers and Bachelors or Above Degree Holders Teachers

\begin{tabular}{|l|l|l|l|l|l|}
\hline Sample & Mean & Number & SD & t-value & Result \\
\hline $\begin{array}{l}\text { Bachelor or above taught } \\
\text { students }\end{array}$ & 42.09 & 191 & 16.24 & 2.389 & $\begin{array}{l}2.389>1.91 \\
\text { at } 0.05 \text { level }\end{array}$ \\
\hline $\begin{array}{l}\text { Under Bachelor taught } \\
\text { students }\end{array}$ & 38.65 & 201 & 12.53 & & \\
\hline
\end{tabular}

Region of Rejection $(\mathrm{R})=\mathrm{t}>1.96$

Degree of freedom $=399$ (two-tailed test) at 0.05 level

The analysis of information mentioned in the above table 1 represents that there were 191 students taught by the Bachelors or above graduate teachers' group. The mean score obtained by them was 42.096 and Standard deviation was 16.24. Similarly, there were 210 students taught by under Bachelor graduate teachers' group. Mean and standard deviation of the achievement scores were 38.65 and 12.53 respectively, obtained by them. This shows that students achievement taught by Bachelor or above degree holders' teachers is more spread than the students' achievement taught by under Bachelor graduate teachers. The obtained calculated $\mathrm{t}$-value was 2.389 which is greater than tabulated value $\mathrm{t} 0.05,399=1.96$. Therefore, the mean score of the students taught by Bachelor or above graduate teachers was significantly higher than that of the students taught by under Bachelor graduate teachers at Grade VIII at 0.05 level.

Here the null hypothesis there is no significant difference between science achievement of the students taught by under Bachelor graduate teacher and Bachelor or above graduate teacher was rejected and the alternative hypothesis of significant difference was accepted.

The second hypothesis was "there is no significant difference between science achievement of the students taught by under Bachelor graduate teacher and Bachelor or graduate and having TPD training teachers of grade VIII.

Table 2

Comparison of Mean Scores of Students Taught by Under Bachelor Graduate Teachers and Bachelor or above Graduate having TPD training teachers of Grade VIII 


\begin{tabular}{|l|l|l|l|l|l|}
\hline Sample & Mean & Number & SD & t-value & Result \\
\hline $\begin{array}{l}\text { Bachelor above TPD } \\
\text { trained taught students }\end{array}$ & 44.87 & 271 & 16.66 & 4.5 & $\begin{array}{l}4.511>1.91 \\
\text { at } 0.05 \text { level }\end{array}$ \\
\hline $\begin{array}{l}\text { Under Bachelor teachers } \\
\text { taught students }\end{array}$ & 38.65 & 210 & 12.53 & & \\
\hline
\end{tabular}

Region of Rejection $=\mathrm{t}>1.96$

$\mathrm{DF}=479$ (two-tailed test) at 0.05 level

The analysis of information mentioned in the above Table 2 represents that there were 271 students in the Bachelor or above graduate and having TPD training teachers' students group. The mean score and Sd. the score obtained by them was 44.87 and 16.66 respectively. Similarly, there were 210 students in under Bachelor graduate teachers' students' group. The mean score and $\mathrm{Sd}$. of the achievement scores obtained by them were 38.65 and 12.53 respectively. This shows that students achievement taught by Bachelor or above and having TPD training teachers is more spread than the students' achievement taught by under Bachelor graduate teachers. The obtained calculate $\mathrm{t}$-value was 4.511 which is greater than the tabulated value ( $\mathrm{t} 0.05,479=1.96$ ). Therefore, the mean score of the student taught by Bachelor or above graduate and having TPD training teachers is higher than the mean score of the students taught by under Bachelor graduate teachers. Thus, the difference in means was found significant at the 0.05 level. It indicated that the mean achievement of the students taught by Bachelor or above graduate and having TPD training teacher was significantly higher than that of the students taught by under Bachelor graduate teachers at Grade VIII at 0.05 level.

The last hypothesis was "there is no significant difference between science achievement of the students taught by Bachelor or above graduate teachers and Bachelor or above graduate and having TPD training teachers of Grade VIII.

Table 3

Comparison of Mean Score of Student Taught by Bachelor or above graduate and having TPD training Teachers and Bachelor or above Degree Holders Teachers

\begin{tabular}{|l|l|l|l|l|l|}
\hline Sample & Mean & Number & SD & t-value & Result \\
\hline $\begin{array}{l}\text { Bachelor above TPD } \\
\text { trained taught students }\end{array}$ & 44.87 & 271 & 16.66 & 1.77 & $\begin{array}{l}1.78>1.96 \\
\text { at } 0.05 \text { level }\end{array}$ \\
\hline $\begin{array}{l}\text { Under Bachelor teachers } \\
\text { taught students }\end{array}$ & 42.09 & 191 & 16.24 & & \\
\hline
\end{tabular}


Region of Rejection $=\mathrm{t}<1.96$

$\mathrm{DF}=460$ (two-tailed test) at 0.05 level

The analysis of information mentioned in the above Table 5 represents that there were 271 students in the Bachelor or above and having TPD training teachers' students group. The mean score and Sd. the score obtained by them was 44.87 and 16.66 respectively. Similarly, there were 191 students in Bachelor or above graduate teachers' students' group. The mean score and Sd. of the achievement scores obtained by them were 42.096 and 16.24 respectively. This shows that students achievement taught by Bachelor or above graduate and having TPD training teachers is more or less spread than the students'achievement taught by Bachelor or above graduate teachers

The obtained calculate t-value was 1.78 which is less than the tabulated value ( $t 0.05,460=1.96$ ). Therefore, the mean score of the student taught by Bachelor or above graduate and having TPD training teachers and the score of the students taught by a bachelor or graduate teachers were approximately the same, not accurate. Thus, the mean difference was found insignificant at the 0.05 level. it indicated that the mean achievement of the students taught by Bachelor or above graduate and having TPD training teachers and Bachelor or above Degree holder teachers were no significant at 0.05 level

Here the null hypothesis of no difference in the mean achievement of the students taught by Bachelors' or above Degree holder teachers and the students taught by Bachelor or above graduate and having TPD training teachers was accepted and the alternative hypothesis of real difference was rejected.

The above findings reveal that the students taught by the teachers with Bachelor or above and having TPD training teacher and Bachelors' or above Degree holder teachers performed significantly better than the students taught by the under Bachelor graduate teachers. However, the performance of the students taught by the teachers with Bachelor or above Degree holder teachers and Bachelor or above and having TPD training teachers performed more or less the same.

\section{Data from Seven-Day Class Observation}

In the second source of data collection of this study was the class observation. The researcher observed the classroom of each category of teachers'for one week. The class was selected by convenience sampling method. The researcher selects Shree Himalayan Secondary School Ghairung-7, Gorkha as a School of Group 
A, Shree Shahid Higher Secondary School SahidLakhan Rural municipality-7, Gorkha as a Group B and finally Shree Saraswati Higher Secondary School Gorkha municipality-7, Gorkha as a Group C School. The class was observed by class observation guidelines for comparing the teacher qualification and teaching effectiveness regarding students' achievement. The researcher himself prepare the classroom observation guidelines based on nine categories namely Content knowledge, Organization of content and class, Rapports with students, Instructional strategies, Presentation skill, Management of class, Respect of students' diversity, Assistance to students and Personal qualities.

The observed data wereanalyzed qualitatively comparatively. The content knowledge of Grade VIII among the three teachers are not different three teachers should good command in subject matter but it is found that the organization of subject matter are slightly different among three groups of the teacher. The under Bachelor graduate teacher was used lecture-based Scattered subject matter. The subject matter organization of Bachelor or above graduate and Bachelor or above graduate and having TPD training teacher was well and good practice of textbook and non-textbook extra problems with a sequential lesson on the content area.

Teachers and students' relation play important role in the teaching-learning process. There is a provable that if students are not learning the teacher should not teach so, rapport with students has great meaning in a professional context. While observing the class among the three groups of teacher the researcher found that all group of the teacher was able to build the way of expressing it. The researcher also found the experience of teaching makes it different for students' rapport. There is a different way of expressing feeling, emotion, students' encouragement among the three group teacher the first group of teacher express the felling emotion and encouragement by physically in the other hand the teacher having Bachelor or above degree can express his rapport by taking the funny way of expressing. The teacher having Bachelor or above and having TPD training qualification is significantly meaningful by expressing both symbolically as well as physical intimacy with true attachment with students.

The teaching techniques among the three group teacher are not significantly different also the students' motivation was different in the classroom. All three groups of teacher used lecture come discussion method. But the part of teacher involvement and students involvement portion are different. In the class of group ' $\mathrm{C}$ ' teacher is more students' centred then compare to the other two groups ' $\mathrm{A}$ ' and group 
'B' teacher. The researcher found the teaching technique of all the teacher is found teacher-centred.

The teacher teaching performance and presentation skill of group $\mathrm{C}$ that is Bachelor or above and having TPD training qualification are better than the other two categories of the teacher. The Bachelor or above graduate and having TPD training teacher had a commanding voice with good classroom management with the creative learning environment and the other two categories of teachers are the same as in the presentation skill. The presentation skill of group A and group B teacher is clear but the classroom environment is somewhat distractive.

The classroom management aspect of three categories teacher is compared in the component of course interaction, leadership and classroom discipline. while observing the class the researcher found that the managing skill of all three groups of the teacher is different through students placement, students discipline and learning environment producing approach group c qualification teacher is successfully managing a classroom with good caring students and classroom environment the teacher had a good commanding and leadership skill with contingency management. The group 'B' teacher approach to classroom management is on the spot but not preplanned there is the commanding and leadership aspect of the teacher is moderate. While the group ' $\mathrm{A}$ ' teacher good command the class control but repressive pedagogy. In the context of diversity management of the class, the higher degree teacher shows positive attitude for management of classroom diversity.

The teacher assistance to students' academic problems was compared among three teachers' the group ' $\mathrm{C}$ ' teacher gives full attention to the students' concern and group 'A' and group 'B' is same and personal qualities are same to all group of teachers. They all posers the overall personal factors' for being a teacher.

From the one-week classroom observation of three different schools having the different qualification of teacher, the researchers found that teacher qualification improves the teaching strategy, proved the knowledge of the content organization, improve the presentation skill and provides assistance in a timely and effective manner to enable the students to proceed with the academic problem.

\section{Students Interview Responses}

For gaining information about the students' perception, the researchers conducted an interview in each observed school among 3 students' all together 9 students were selected from 3 schools. The interview was conducted based on interview guidelines. 
This interview focusses the students' perception and level of satisfaction in references to the academic qualification of the teacher. The researcher categories the interview guidelines into 9 different categories.

\section{Interview responses of Group 'A' students}

The Researcher selected three students from Shree Himalaya Secondary School, Ghairung-7, Gorkha as for interview as a group A that is students' of under Bachelor graduate teacher. The three students of group 'A' was taken among them one wasa girl and two boy students were selected.

Student A1: Student A1 is 13 years girl. She lives in Ghairung-8. She has to walk half an hour to reach the school. She said that "I am feeling positive about science, relatively chemistry is difficultly for me. The teacher taught understanding way. Our practice is less so I did not get more marks to improve the achievement level in science more practice at home is required. The teacher behaves me positively. The teacher taught us by dong one problem on the board and give to solve similar problems. I am asking only difficult problems for the teacher. I don't have the habit of asking a question to the teacher. The classroom learning climate is interactive among teacher and student only".

She had a positive attitude towards science. She said that chemistry was a difficult area of science. She had satisfiedwith her teacher. The teacher did positive behaviour with her. She completes her homework on time and does not shy while asking difficult problem with the teacher and she said that the present qualification of teachers is sufficient for her study. She doesn't know her science teacher's qualification but the present qualification of the teacher is better.

Student A2: Students A2 is a 13 years old boy. He lives in Chisepani. In the evening he has to help his mother in household work but he has sufficient time to complete his homework. He said that "I feel good in science learning. I am unknown about my science teacher qualification but he teaches us goodly. But there is different in teaching methodology of our teacher and the other teacher whose teaching in the higher class. I am positive out my teacher teaching style and our science achievement is increase by thoroughly practice at home. "He had a strong positive attitude towards science. He said that chemistry expression was a difficult area of science. He felt teacher qualification does not play a role in teaching style but play a role in content knowledge. He was satisfied with his teacher. 
Student A3: The students A3 is a 13 years old boy. He lives in Ghairung. He said that "I feel science is an easy subject than other our teacher teaching in a funny way. I am unaware of my teacher qualification but he is better. He teaches us more labourers and he is repressive than another teacher. He solves the problems posed by us. I am feeling comfortable to learn science with him."

He was strongly positive attitudes towards science and science teacher. $\mathrm{He}$ claims that the teacher provided a strong foundation for learning in class. Although the teacher qualification is significant in education he gives there is no effect of teacher qualification in his education both under Bachelor graduate and Bachelor or above graduate teacher taught the same way in class and he is satisfied with his under Bachelor graduate science teacher.

\section{Interview responses to Group 'B' students}

The researchers selected 3 students from Shree Shahid higher secondary school for an interview as a group B that is students of Bachelor graduate teacher. The interview data was presented here with thematic form.

Student B1: Student B1 is a 14 years old girl. She lives in Chapthok. She said that "I feel science is difficult. The teacher does not present the lesson effectively. In the teaching time, we do not understand what the teacher told us about the problems. The teacher is not a judge for the weak students. I do not give them time to learn science at home. I had enough time to complete my homework."

She hasn't had a positive attitude towards science. She had a negative attitude toward her science teacher. She was not able to remember any definition related toscience. She said that teacher qualification is significant but her science teacher did not play his role significantly. While asking the difficult question the teacher response is negative. So, the teacher qualification as wells professional quality is significant. However, she did not found these qualities in teachers.

Student B2: Student B1 is a 14 years old girl. She lives in Lakhedada now. She said that "I feel science is relatively difficult than another subject. The teacher taught us in a moderately good. His teaching style is directly present the lesson by rememberingthe definition. There is no practical class and solve all problems of the textbook by describing. The students are passive. He presents the lesson fast so I feel difficult to grasp the content. I don't know my teacher's qualification. I give half an hour to learn science at home." 
She felt science is a relatively difficult but positive attitude about her teacher. She was medium students in the class. She claims that her teacher teaching style needed to improve in term of speed. While focusing on teacher qualification she said teaching style is important than the teacher qualification.

Student B3: Student B3 is a 13 years old boy. He lived in Makaipur. He said that "I feel science is easy if we did more practice. The teacher teaches us by telling definition first then solve the problems by describing. I am feeling positive about his teaching method. He helps me and solves the problem asked by me and I did not give more time to read science at home." He had a positive attitude towards science. He said that teacher qualification is important in teaching. He is confident and gets full help from the teacher.

\section{Interview responses to Group 'C' students}

The researchers selected 3 students from Shree Saraswati higher secondary school as a students' taught by Master's graduate teachers. The thematic data is present below.

Student C1: Student C1 is a 14 years old boy. He lived in patechour. He has to walk 45 minutes to reach the school. He said that "I feel science is easy. He did one hour to read science at home daily. The teacher teaches meaningfully. The teacher cooperates with students and gives extra effort to learn more problems than textbook the teacher teaches sequentially and effective way. I fully understand the concepts of science. I don't know my teaching qualification."

He had a strong positive attitude towards science. The attitude of $\mathrm{C} 1$ students towards science teacher is brilliant in academic degree and teaching style. He claims that his teacher did more effect to teach science. He is satisfied with his science teacher.

Student C2: Student C2 is a 13 years old girl. She lives in Hospitalchok. She said that "I feel that science is an easy subject. The teacher excitingly taught us. The pedagogical method of the teacher is good. The most like part of science is biology. I have $5 \mathrm{pm}$ to $7 \mathrm{pm}$ for completing homework and practising. The teacher taught us science contentpractically. The teaching style is the most important factors in teacher good behaviours. I feel easy and positive towards solving homework." She had a positive attitude towards science. She had no claims with her science teacher. She said that her science is better relatively better than another subject teacher. She was satisfied with her science teacher. She said teacher qualification is important in science learning. 
Student C3: Students C3 is a 14 years old boy. He said that "I feel science is an essay and most like subject. The most like part of science is biology and physics and chemistry is somewhat difficult. The teacher createsa good environment for learning and givesa positive direction for learning. The relation between the teacher and students are good. The teacher gives us homework and checks it regularly. I am exciting while teaching. The extra effort is need for securing good marks in an examination. The good aspect of the teacher is creating a collaborative environment and answering of the question while asking."

He had a positive attitude toward science and science teacher. He felt interesting while learning science. He said that his teacher taught science interestingly and no claim towards his teacher teaching style. He said that teacher qualification had a positive effect on students learning and he was satisfied with his teacher and his qualification.

\section{Discussion}

This study was concerned with the comparative study of science achievement of Grade VIII students related to their teachers' qualification in Gorkha district. The revision of DLE result of Gorkha district in the academic year 2016/17 from 15 public schools, 672 students were proceeded for secondary data collection. The procedure used in the collection of data was the recording of the scores of the students in DLE examination 2016/17. The scores obtained by the students were classified into three categories: the scores of students taught by bachelor's or above holders and having TPD training teachers, bachelor's or above degree holders and under bachelor's graduate teachers. Under these categories, the mean score of the students of five schools taught by bachelor's or above degree holder and having TPD training teachers, the mean score of the students of next five schools taught by bachelor's or above graduate teachers, and the mean score of the students of last five schools taught by under bachelor's graduate teachers were calculated. After this achievement level of the students taught by under bachelor's graduate teachers were compared with an achievement level of the students taught by bachelor's or above graduate teachers, the achievement level of the students taught by under bachelor's graduate teachers was compared with an achievement level of students taught by bachelor's or above graduate and having TPD training teachers and the achievement level of the students taught by bachelor's or above graduate teachers was compared with the students taught by bachelor's or above degree holder and having TPD 
training teachers. Similarly, the primary data was collected through classroom observation and students interview guideline. For classroom observation, 3 schools having a different level of qualification were selected. The classroom observation data was collected through classroom observation guideline. The classroom observation result shows that there is a pedagogical knowledge difference between the three groups of the teachers. The bachelor's or above graduate and having TPD training teacher were more student-centred than other groups of teachers, but there was no difference in content knowledge observed by researchers among the three groups of teachers.

Interview from three students of each observed school was conducted by the researchers with the help of interview guideline. The interview result shows that the pedagogical part of the teacher is important than qualification and indicated that students' satisfaction does not depend on teacher qualification.

To test the statistical difference of the mean scores between any two groups of students taught by teachers of different levels of qualifications, t-test was used. Based on the analysis and interpretation of data, the findings were as below.

The mean difference was significant at the 0.05 level of confidence. From the table above we found that the performance of the students taught by the bachelor's degree or above and having TPD and bachelor's or above graduate teachers were significantly improved when compared to the performance of the student taught by the under bachelor's graduate teachers. But the performance of the student taught by bachelor's or above degree holders having TPD training science teachers and bachelor's above degree holder science teachers were more or less the same. The classroom observation and students' interview result shows that the teacher qualification has impacted on the teaching strategy, the teacher qualification help the content organization, diversity management and the students' perception doesn't depend on the teacher qualification but it depends on teaching strategy.

\section{Conclusion}

Based on the findings, this study showed that teachers' qualification and professional development plays an important role in science achievement of students. Science achievement of the students taught by bachelor's or above degree holders and having TPD training and bachelor's or above degree holder teachers were found higher than that of the students taught by under bachelor's graduate science teachers. 
Therefore, this study suggests to upgrade the academic degree of the teacher with at least a bachelor's graduate and implement TPD programme to improve the science achievement scores of basic level. On the other hand, student's satisfaction did not depend only on the teacher qualification but pedagogical consideration is an important aspect of teaching. So pedagogical improvement training, workshop, seminars and higher qualified teachers are required to increase the students' achievement and satisfaction level.

\section{References}

Acharya, B. R. (2015). Foundation of mathematics education. Kathmandu: Dikshant Prakashan.

Affouneh, S., Salha, S., Burgos, D., Khlaif, Z. N., Saifi, A.G., Mater, N.G, Odeh, A. (2020). Factors that foster the deter STEAM professional development among teachers. Science Education. 1-16. https://doi.org/10.1002/sce.21591

Avramidis, E., \&Kalyva, E. (2007). The influence of teaching experience and professional development on Greek teachers' attitudes towards inclusion. European Journal of Special Needs Education, 22(4), 367-389. http://www.tandfonline.com/loi/rejs20

CERID, (1996). A comparative study of trained and untrained teachers. Kathmandu, Nepal: Author.

Creswell, J. W. (2012). Educational research: Planning, conducting and evaluating quantitative and qualitative research (4 ed.). Boston, MA: Pearson Education, Inc

Darling-Hammond, L. (1999). Teacher quality and student achievement. A review of state policy evidence. Research Report R-99-1, Center for the Study of Teaching and Policy, University of Washington.

Hopkins, D., \& Harris, A. (1997). Improving the quality of education for all. Support for Learning, 12(4), 147-151. doi:10.1111/1467-9604.00035

Koirala, K. P. (2074 BS). How science teaching is different in public and private schools. Does different is seen in classroom practice? Education, 34(1), 209219. Kathmandu, Bhaktapur: Curriculum Development Centre.

Koirala, K.P. (2019). Use of information and communication technology(ICT) in teaching and learning in Nepalese classroom: Challenge and opportunity. Journal of Education and Practice, 10(7), 1-5. doi: 10.7176/JEP/10-7-01 
Koirala, K. P. (in press). Multicultural classroom teaching in Nepal: Perspectives and practices of a secondary level science teacher. Cultural Studies of Science Education.

Lockheed, M.E. (1988). School effects on students achievement in Nigeria and Swaziland (Working Paper), The World Bank.

MoE. (2016). School Sector Development Plan 2016/17-2022/23. Kathmandu: Autor. MoEST. (2076 b). National Science Technology and Innovation Policy. Kathmandu, Nepal: Author.

MoEST. (2076a). National Education Policy. Kathmandu, Nepal: Author.

Mohan, R. (2013). Teacher Education. New Delhi: PHI Learning PVT.

NCED, (2006). Effective study of primary teacher training in Nepal. Sanothimi:

Author.

Sharma, C., \& Sharma, N. (2066 BS). Philosophical and sociological foundation of Education. Kathmandu: M.K. Publishers \& Distributors.

Sood, J. K. (1989). Teaching of science. Chandigrah: Kohli Publishers. 